\title{
Tissue-specific bioactivity of soluble tendon-derived and cartilage-derived extracellular matrices on adult mesenchymal stem cells
}

Benjamin B. Rothrauff ${ }^{1,2}$, Guang Yang ${ }^{1,3}$ and Rocky S. Tuan ${ }^{1,2,3^{*}}$

\begin{abstract}
Background: Biological scaffolds composed of tissue-derived extracellular matrix (ECM) can promote homologous (i.e., tissue-specific) cell differentiation through preservation of biophysical and biochemical motifs found in native tissues. Solubilized ECMs derived from decellularized tendon and cartilage have recently been promoted as tissuespecific biomaterials, but whether tissue-specific bioactivity is preserved following solubilization is unknown. This study explored the tissue-specific bioactivity of soluble decellularized tendon and cartilage ECMs on human bone marrow-derived mesenchymal stem cells (MSCs) presented across different culture microenvironments, including two-dimensional (2D) tissue culture plastic, aligned electrospun nanofibers, cell pellets, and cell-seeded photocrosslinkable hydrogels.
\end{abstract}

Methods: Tendon and cartilage ECMs were decellularized using established methods and solubilized either via pepsin digestion or urea extraction. The effect of soluble ECMs on cell proliferation and differentiation was initially explored by supplementing basal medium of human MSCs cultured on 2D tissue culture plastic. In subsequent experiments, MSCs were cultured on aligned electrospun nanofibers, ascell pellets, or encapsulated within photocrosslinkable methacrylated gelatin (GelMA) hydrogels. Urea-extracted tendon and cartilage ECMs were added as supplements.

Results: Pepsin-digested ECMs did not promote homologous differentiation in human MSCs, whether provided as a medium supplement or three-dimensional (3D) hydrogels. In contrast, urea-extracted ECMs tended to promote tissuespecific differentiation of MSCs cultured in 2D and 3D microenvironments. The application of the small molecule TGF- $\beta$ signaling inhibitor SB-431542 largely negated the tissue-specific gene expression patterns mediated by tendon and cartilage ECMs. This suggests that the action of endogenous TGF- $\beta$ was required, but was not sufficient, to impart tissue-specific bioactivity of urea-extracted ECMs. When urea-extracted cartilage ECM was incorporated within a photocurable GeIMA hydrogel it independently enhanced chondrogenesis in encapsulated MSCs, and showed additive prochondrogenesis upon TGF- $\beta$ supplementation in the medium.

Conclusions: Urea-extracted ECM fractions of decellularized tendon and cartilage are soluble supplements capable of enhancing tissue-specific differentiation of adult stem cells.

Keywords: Decellularized extracellular matrix, Tendon, Cartilage, Differentiation

\footnotetext{
* Correspondence: rst13@pitt.edu

${ }^{1}$ Center for Cellular and Molecular Engineering, Department of Orthopaedic

Surgery, University of Pittsburgh School of Medicine, 450 Technology Drive,

Room 221, Pittsburgh, PA 15219, USA

${ }^{2}$ McGowan Institute for Regenerative Medicine, University of Pittsburgh,

Pittsburgh, PA 15219, USA

Full list of author information is available at the end of the article
} 


\section{Background}

Injuries to tendon and cartilage present a persistent clinical challenge given the poor intrinsic healing capacity of these tissues. Tissue engineering strategies, which employ the independent or combined application of cells, scaffolds, or biomolecules, have shown promise in restoring the structure and function of both tendon $[1,2]$ and cartilage $[3,4]$. Biomimetic scaffolds, including aligned electrospun nanofibers [5, 6] and hydrogels $[7,8]$, possess ultrastructural motifs respectively found in native tendon and cartilage which are capable of directing differentiation of mesenchymal stem cells (MSCs) towards a particular musculoskeletal lineage. These effects are further enhanced by exposure to soluble biomolecules known to orchestrate tendon and cartilage development [9-11]. In particular, the transforming growth factor beta (TGF- $\beta$ ) superfamily plays an essential role in both tenogenesis [12] and chondrogenesis [13], mediating divergent effects depending upon additional microenvironmental cues [14]. At present, an incomplete understanding of tendon and cartilage development and homeostasis limits tissue engineering approaches to regenerate these tissues [15].

On the other hand, tissues and organs can be decellularized to mitigate an adverse immune response against foreign cells while theoretically preserving the ultrastructural, mechanical, and biochemical motifs of the native tissue [16]. To that end, decellularized tendon and cartilage may serve as the ideal scaffold to promote homologous (i.e., tissue-specific) differentiation of endogenously recruited or exogenously delivered progenitor cells $[17,18]$. Indeed, decellularized tendon [19-21] and cartilage [22, 23] tissues have been found to promote tissue-specific differentiation when seeded with MSCs. Nevertheless, the dense collagenous architecture comprising the extracellular matrix (ECM) of these tissues can necessitate the use of relatively harsh decellularization methods to sufficiently remove native cells which can compromise native tissue ultrastructure and biochemical composition. Even with sufficient removal of cellular content, the dense ECM serves as a barrier for cell infiltration, with cells often localized to the tissue surface [23, 24]. In addition, the use of whole decellularized tissue as grafts requires surgical reconstruction/ transplantation (as opposed to repair), with resulting limitations in treating small or irregularly shaped defects.

In an effort to overcome these limitations while retaining the tissue-specific bioactivity inherent in the ECM, decellularized tissues have been processed into powders, which can be molded into distinct geometric shapes $[25,26]$, or suspended in a hydrogel [27-29]. Alternatively, ECM powders can be solubilized with enzymatic or chaotropic agents, resulting in an injectable solution that can be combined with a diverse array of biomaterials. Pepsin-digested tendon [30, 31] and cartilage [32, 33] hydrogels have been shown to undergo thermoresponsive gelation at body temperature and are cytocompatible. However, the effect of pepsin, a nonspecific protease, on the tissue-specific bioactivity of tendon and cartilage ECM remains unknown. While Keane et al. [34] reported that pepsin-digested esophageal ECM hydrogels supported esophageal stem cell migration and organoid formation to a greater extent than heterologous ECM hydrogels, Lin et al. [35] found that a pepsin-digested extract of decellularized MSC sheets provided no additional benefit over collagen (COL) type I hydrogels; conversely, a urea-extracted fraction enhanced MSC attachment, spreading, proliferation, migration, and multi-lineage differentiation. Similarly, Zhang et al. [36] and Yang et al. [37] independently reported that urea-extracted fractions of decellularized ECM from diverse tissues were capable of promoting tissue-specific differentiation.

In this study, soluble decellularized tendon and cartilage ECMs were initially prepared by pepsin digestion or urea extraction. As early experiments with twodimensional (2D) cultures suggested the superiority of urea-extracted over pepsin-digested solutions in terms of supporting proliferation and tissue-specific differentiation of MSCs, the bioactivities of urea-extracted ECM solutions were further investigated across several threedimensional (3D) conditions commonly employed for cell-based tissue engineering and regeneration, including electrospun nanofibers, pellet culture, and photocrosslinked methacrylated gelatin (GelMA) hydrogels. Supplementation of culture medium with TGF- $\beta 3$ served as a positive control. We hypothesized that urea-extracted ECM fractions would promote tissue-homologous differentiation of MSCs under multiple 3D culture conditions.

\section{Methods \\ Overview}

Tendon and hyaline cartilage were procured from bovine hindlimbs and subsequently decellularized and characterized. Tendon and cartilage ECMs were then solubilized through either acid-pepsin digestion (tAP and cAP, respectively) or urea extraction (tECM and $\mathrm{CECM}$, respectively), and their respective effects on human MSC proliferation and gene expression were determined in 2D culture. MSCs were cultured as pellets, seeded on aligned nanofibrous scaffolds, or encapsulated in photocrosslinked GelMA hydrogels, and exposed to media supplemented with TGF- $\beta 3$, urea-extracted tendon ECM (tECM), or urea-extracted cartilage ECM (cECM). Assays for gene expression, histology, and biochemical composition were performed to assess tissue-specific bioactivities of the supplements. Additionally, the effect 
of inhibiting endogenous TGF- $\beta$ present in ureaextracted ECM fractions, using the small molecule inhibitor SB-431542, was assessed using pellet cultures.

\section{Decellularization of tendon and cartilage}

Patella tendon and articular cartilage were procured from hindlimbs of 6-8 week old cows (Research 87, Boylston, MA, USA) and stored at $-20{ }^{\circ} \mathrm{C}$ in a protease inhibitor solution composed of phosphate-buffered saline (PBS; Gibco, Grand Island, NY, USA) supplemented with $5 \mathrm{mM}$ ethylenediaminetetraacetic acid (EDTA; Sigma-Aldrich, St. Louis, MO, USA) and $0.5 \mathrm{mM}$ phenylmethylsulfonyl fluoride (PMSF; Sigma-Aldrich) until use. Upon thawing, tissues were minced $\left(8-27 \mathrm{~mm}^{3}\right)$ and cryomilled (Spex Freezer Mill 8670, Metuchen, NJ, USA). Four grams of wet tissue powder were suspended in $40 \mathrm{~mL}$ of protease inhibitor solution containing $1 \%$ Triton X-100 (Sigma-Aldrich) and agitated for $24 \mathrm{~h}$ at $4{ }^{\circ} \mathrm{C}$, followed by three washes for $30 \mathrm{~min}$ each in PBS. Tissue powders were subsequently exposed to $40 \mathrm{~mL}$ of Hank's buffered salt solution (HBSS; ThermoFisher Scientific, Pittsburgh, PA, USA) supplemented with $200 \mathrm{U} / \mathrm{mL}$ DNase and $50 \mathrm{U} / \mathrm{mL}$ RNase (Worthington, Lakewood, NJ, USA) for $12 \mathrm{~h}$ at room temperature. Decellularized powders were then washed six times with $\mathrm{PBS}$ and characterized for histological appearance and biochemical composition.

\section{Solubilization of decellularized ECM Pepsin digestion}

Decellularized tendon and cartilage ECM powders were enzymatically digested in a solution of $1 \mathrm{mg} / \mathrm{mL}$ porcine pepsin (Sigma-Aldrich) in $0.01 \mathrm{~N} \mathrm{HCl}$ for $48 \mathrm{~h}$ at room temperature under continuous stirring. For use as a medium supplement, digested tendon and cartilage ECM were neutralized by the addition of one-tenth digest volume of $0.1 \mathrm{~N} \mathrm{NaOH}$ and one-ninth digest volume of $10 \times$ PBS while keeping the samples at $4{ }^{\circ} \mathrm{C}$. To form 3D hydrogels, $\mathrm{pH}$-neutralized digests were warmed to $37{ }^{\circ} \mathrm{C}$ for $1 \mathrm{~h}$, as reported previously [34, 38].

\section{Urea extraction}

A water-soluble fraction of tendon and cartilage ECM was obtained through urea extraction, as previously described [37]. Briefly, $4 \mathrm{~g}$ of wet decellularized ECM powder was agitated for 3 days at $4{ }^{\circ} \mathrm{C}$ in $40 \mathrm{~mL}$ of $3 \mathrm{M}$ urea dissolved in water. The suspension was centrifuged for $20 \mathrm{~min}$ at $1500 \mathrm{~g}$ and the supernatant was transferred to benzoylated tubing (Sigma-Aldrich) and dialyzed against $\mathrm{dd}_{2} \mathrm{O}$ for 2 days at $4{ }^{\circ} \mathrm{C}$, changing the water every $8 \mathrm{~h}$. The dialyzed ECM extract was transferred to centrifugal filter tubes (3000 MWCO; EMD Millipore, Billerica, MA, USA) and spin-concentrated approximately 10-fold at $1500 \mathrm{~g}$ for $60 \mathrm{~min}$. The final ECM extract was filter-sterilized through a PVDF syringe filter unit (0.22 $\mu \mathrm{m}$; EMD Millipore). Protein concentration was determined by BCA assay (ThermoFisher Scientific) and aliquots of $1 \mathrm{mg} / \mathrm{mL}$ were stored at $-80{ }^{\circ} \mathrm{C}$ until further use. Before use in experimental studies, aliquots prepared from three different batches were pooled.

\section{SDS-PAGE and growth factory analysis of soluble ECM}

Samples of native tendon and cartilage ECMs, and their corresponding urea-extracted and pepsin-digested extracts, were suspended in TM buffer (Total Protein Extraction Kit, EMD Millipore); $30 \mu \mathrm{g}$ total protein was mixed with SDS loading buffer and reducing agent (NuPAGE; Life Technologies, Carlsbad, CA, USA) and heated for $10 \mathrm{~min}$ at $70{ }^{\circ} \mathrm{C}$. Protein was loaded into a pre-cast 10-well NuPAGE 4-12\% Bis-Tris Minigel (Life Technologies) and separated by electrophoresis in MOPS running buffer for $50 \mathrm{~min}$ at constant $200 \mathrm{~V}$. The gel was stained with SimplyBlue ${ }^{\mathrm{TM}}$ SafeStain (Life Technologies) for $1 \mathrm{~h}$, washed several times in water, and photographed using a CCD camera gel imaging system (FOTODYNE, Hartland, WI, USA).

Additionally, the growth factor contents of the soluble ECM preparations were determined using a Human Growth Factor Array (RayBiotech, Norcross, GA, USA) according to the manufacturer's instructions.

\section{MSC isolation}

Human MSCs were obtained as previously described [35], with Institutional Review Board approval (University of Washington and University of Pittsburgh). MSC populations isolated from individual patients were routinely validated as capable of osteogenic, adipogenic, and chondrogenic differentiation (data not shown). All experiments were performed with passage 3 (P3) MSCs. MSCs from three patients (56-year-old male, 56-year-old female, 59year-old male) were pooled for this study.

Bioactivity of soluble ECM in two-dimensional cell culture To determine the effect of soluble ECM preparations on MSC morphology, proliferation, and metabolism, $1 \times 10^{3}$ cells $/ \mathrm{cm}^{2}$ were suspended in growth medium (Dulbecco's modified Eagle's medium (DMEM), 10\% v/v fetal bovine serum (FBS), 1\% v/v penicillin-streptomycinfungizone (PSF); Life Technologies) and plated in six-well culture plates. One day following cell seeding, growth medium was replaced with serum-free medium (DMEM, $1 \%$ PSF, $1 \%$ insulin-transferrin-selenium (ITS); Life Technologies) with or without additional supplementation. There were six medium conditions: (1) serum-free control; (2) 10 ng/mL TGF- 33 (Peprotech, Rocky Hill, NJ, USA); (3) $50 \mu \mathrm{g} / \mathrm{mL}$ tAP; (4) $50 \mu \mathrm{g} / \mathrm{mL}$ tECM; (5) $50 \mu \mathrm{g} / \mathrm{mL}$ cAP; and (6) $50 \mu \mathrm{g} / \mathrm{mL}$ cECM. Media were 
changed every 2 days. On days 1, 3, and 7, an MTS assay (CellTiter $96^{\circ} \mathrm{AQ}_{\text {ueous }}$ Non-Radioactive Cell Proliferation Assay; Promega, Madison, WI, USA) was performed according to the manufacturer's instructions. To determine the effects of soluble ECM on gene expression, $2 \times 10^{4}$ cells $/ \mathrm{cm}^{2}$ were plated in sixwell culture plates and cultured up to 7 days, as described above. On days 1, 3, and 7, cell lysates were collected for quantitative real-time polymerase chain reaction (qPCR; described below). As significant differences across treatment groups were only seen at day 3 , expression levels were normalized against day 3 controls.

\section{qPCR}

In 2D cultures, total cellular RNA was isolated using an RNeasy Plus Mini Kit (Qiagen, Valencia, CA, USA) and reverse transcribed into cDNA through use of the SuperScript III first-strand synthesis kit (ThermoFisher Scientific). For 3D cultures, RNA isolation was preceded by homogenization of samples in Trizol (ThermoFisher Scientific). qPCR was performed using $\mathrm{SYBR}^{\circ}$ Green master mix (Applied Biosystems, Foster City, CA, USA) on a StepOnePlus Real-Time PCR system (Applied Biosystems). Relative expression of each target was calculated using the $\triangle \Delta \mathrm{C}_{\mathrm{T}}$ method with the arithmetic average of GAPDH and 18S rRNA expression used as the endogenous reference. Target gene primer sequences are listed in Additional file 1 (Table S1).

\section{Bioactivity of pepsin-digested ECM as three-dimensional hydrogels}

To evaluate the bioactivity of pepsin-digested ECMs as $3 \mathrm{D}$ hydrogels, $1.0 \times 10^{6} \mathrm{MSCs} / \mathrm{mL}$ were suspended in cold, $\mathrm{pH}$-neutralized hydrogels consisting of the following groups: (1) collagen type I (Control; $\mathrm{PureCol}^{\circ} \mathrm{EZ}$ Gel, Advanced Biomatrix, Carlsbad, CA, USA); (2) tAP; and (3) cAP (all at a final concentration of $5 \mathrm{mg} / \mathrm{mL}$ ). To induce thermogelation, MSC-seeded hydrogels were incubated for $1 \mathrm{~h}$ at $37^{\circ} \mathrm{C}$, after which reduced-serum medium (DMEM, 2\% FBS, 1\% PSF) was added. Constructs were collected on day 7 for qPCR.

\section{Bioactivity of urea-extracted ECM in culture of MSC-seeded aligned nanofibers}

Sheets of aligned nanofibers were fabricated from a solution of poly- $\varepsilon$-caprolactone (PCL; $\quad M W=70-90 \quad k$; Sigma-Aldrich) prepared at $15 \% \mathrm{w} / \mathrm{v}$ in $1: 1(\mathrm{v} / \mathrm{v})$ tetrahydrofuran (THF; Sigma-Aldrich):dimethylformamide (DMF; ThermoFisher Scientific) as described previously [39]. The PCL solution was loaded into $10-\mathrm{mL}$ syringes and extruded through an 18-gauge blunt tip needle at $3.0 \mathrm{~mL} / \mathrm{h}$ using a syringe pump (PY2 70,2209, Harvard Apparatus, Holliston, MA, USA). The needle tip was placed $10 \mathrm{~cm}$ from a custom-designed cylindrical mandrel, which rotated at a surface velocity of $10 \mathrm{~m} / \mathrm{s}$. A DC potential of 10-18 kV (Gamma High Voltage, Ormond Beach, FL, USA) was applied to the polymer solution while an $8 \mathrm{kV}$ potential was applied to two aluminum shields placed perpendicular to the mandrel axis but parallel to the needle axis, narrowing the width of the aligned nanofibrous sheet collected on the grounded mandrel.

MSCs were seeded on PCL nanofibers at $6 \times 10^{4}$ cells/ $\mathrm{cm}^{2}$ and cultured for 14 days in serum-reduced (2\% FBS) culture medium supplemented with $50 \mu \mathrm{g} / \mathrm{mL}$ ascorbate-2-phosphate (Sigma-Aldrich). There were four medium conditions: (1) control; (2) $10 \mathrm{ng} / \mathrm{mL}$ TGF- $\beta 3$; (3) $50 \mu \mathrm{g} / \mathrm{mL}$ tECM; and (4) $50 \mu \mathrm{g} / \mathrm{mL}$ cECM (with medium changes every 2 days). On day 14, constructs were collected for qPCR or immunofluorescence staining. qPCR was performed as described above. For immunofluorescence straining, constructs were fixed with $4 \%$ paraformaldehyde, and blocked with $1 \%$ bovine serum albumin (BSA) and $22.5 \mathrm{mg} / \mathrm{mL}$ glycine in PBS-T. Constructs were incubated with goat anti-tenomodulin (Tnmd; 1:50, sc49325 Santa Cruz Biotechnologies, Dallas, TX, USA) overnight at $4{ }^{\circ} \mathrm{C}$. AlexaFluor 488 chicken anti-goat (Invitrogen, ThermoFisher Scientific) at a 1:500 dilution was used as the secondary antibody. Constructs were nuclear-counterstained with 4,6diamidino-2-phenylindole, dilactate (DAPI; Invitrogen) and imaged using a confocal microscope (Olympus FluoView 1000).

\section{Bioactivity of urea-extracted ECM in culture of MSC pellets}

MSCs $\left(2.5 \times 10^{5} / \mathrm{mL}\right.$ in $200 \mu \mathrm{L}$ chondrogenic medium: DMEM, 1\% PSF, 1\% ITS, $0.1 \mu \mathrm{M}$ dexamethasone, $40 \mu \mathrm{g} /$ $\mathrm{mL}$ proline, $50 \mu \mathrm{g} / \mathrm{mL}$ ascorbate-2-phopshate) were distributed into conical 96-well plates and centrifuged for $10 \mathrm{~min}$ at $300 \mathrm{~g}$. Pellets were cultured for 21 days in one of four medium conditions: (1) control; (2) $10 \mathrm{ng} / \mathrm{mL}$ TGF- 33 ; (3) $50 \mu \mathrm{g} / \mathrm{mL} \mathrm{tECM}$; and (4) $50 \mu \mathrm{g} / \mathrm{mL} \mathrm{cECM}$ (with medium changes every 2 days). At day 21, pellets were collected for qPCR, histology, and biochemical analysis.

\section{Effect of TGF- $\beta$ inhibition on bioactivity of urea-extracted ECM}

MSC pellets were cultured for up to 21 days under one of four conditions, as described below. The small molecule TGF- $\beta$ inhibitor SB-431542 (Sigma) [40] was added at a final concentration of $10 \mu \mathrm{M}$ approximately $1 \mathrm{~h}$ prior to adding the appropriate culture supplement (i.e., $10 \mathrm{ng} / \mathrm{mL}$ TGF- $\beta 3,50 \mu \mathrm{g} / \mathrm{mL}$ tECM, $50 \mu \mathrm{g} / \mathrm{mL}$ cECM). Media were changed every 2 days. qPCR, histology, and analysis of biochemical composition were 
performed on day 21. As supplementation with SB431542 did not dramatically affect gene expression patterns compared to pellets cultured in control medium (i.e., without SB-431542), relative fold changes are shown normalized against the control + SB-431542 medium condition for clarity.

\section{Bioactivity of cartilage ECM in MSC-seeded GeIMA hydrogels}

GelMA was synthesized by adapting a previously established protocol [8]. Briefly, $15 \mathrm{~g}$ of gelatin (Type A, from porcine skin; Sigma-Aldrich) was dissolved in $500 \mathrm{~mL}$ deionized $\mathrm{H}_{2} \mathrm{O}$ at $40{ }^{\circ} \mathrm{C}$, and then $15 \mathrm{~mL}$ of methacrylic anhydride (Sigma-Aldrich) was added dropwise under vigorous stirring. The mixture was placed at $37{ }^{\circ} \mathrm{C}$ in an orbital shaker at $150 \mathrm{rpm}$ for $24 \mathrm{~h}$. The resulting GelMA was dialyzed for 4 days against $\mathrm{H}_{2} \mathrm{O}$ at room temperature using 2000 NMWCO dialysis tubing (Sigma-Aldrich) to completely remove all low-molecularweight byproducts, with changes in $\mathrm{H}_{2} \mathrm{O}$ twice daily. After lyophilization, the product was stored at $-20{ }^{\circ} \mathrm{C}$ until future use. Prior to use, GelMA was reconstituted at $10 \%$ $(\mathrm{w} / \mathrm{v})$ in HBSS. The visible light-sensitive photoinitiator lithium phenyl-2,4,6-trimethylbenzoylphosphinate (LAP) was then added at $0.25 \% \mathrm{v} / \mathrm{v}$ and dissolved by gentle shaking at room temperature. MSCs were homogeneously suspended in one of two hydrogels: (1) $10 \%$ w/v GelMA (control); or (2) 10\% w/v GelMA supplemented with $500 \mu \mathrm{g} / \mathrm{mL}$ cECM (cECM) at a concentration of $20 \times 10^{6}$ cells $/ \mathrm{mL}$. Before gelation, MSCseeded hydrogels $(\sim 50 \mu \mathrm{L})$ were distributed to cylindrical silicone molds measuring 5-mm diameter $\times 2$-mm depth. To induce photogelation, hydrogels were exposed to 2 min of visible light (450-490 nm). MSC-seeded hydrogels were then removed from the silicone molds and transferred to six-well plates previously coated with silicone (Sigmacote, Sigma-Aldrich) to prevent cell migration and adhesion onto the plastic surface. Constructs were cultured up to 21 days in chondrogenic medium with or without an additional $10 \mathrm{ng} / \mathrm{mL}$ TGF- $\beta 3$ (Peprotech) supplementation. Medium was changed every 2 days. Constructs were collected on days 7 and 21 for analysis of gene expression and biochemical content.

\section{Histology and immunofluorescence}

All samples collected for histology (excluding electrospun nanofibers) were fixed in $10 \%$ phosphate-buffered formalin, serially dehydrated, embedded in paraffin, and sectioned (6 $\mu \mathrm{m}$ thickness) with a microtome (Leica RM2255, Leica Biosystems, Buffalo Grove, IL, USA). Samples were rehydrated and stained with hematoxylin and eosin (H\&E; Sigma-Aldrich), Safranin O and Fast Green (Electron Microscopy Sciences, Hatfield, PA, USA), or DAPI (Life Technologies, Carlsbad, CA, USA).
For samples used for immunofluorescence staining, antigen retrieval entailed incubation with chondroitinase ABC $(100 \mathrm{mU} / \mathrm{mL})$ and hyaluronidase $(250 \mathrm{U} / \mathrm{ml})$ suspended in $0.02 \% \mathrm{BSA}$ for $30 \mathrm{~min}$ at $37{ }^{\circ} \mathrm{C}$. Samples were incubated overnight at $4{ }^{\circ} \mathrm{C}$ with the following primary antibodies: 1:400 rabbit anti-collagen type II (ab34712, Abcam, Cambridge, MA, USA), 1:400 mouse anticollagen type I (5D8-G9/Col1, ThermoScientific), or 1:400 mouse anti-collagen type X (ab49945, Abcam). Samples were incubated in one of two secondary antibodies for $1 \mathrm{~h}$ at room temperature: 1:500 AlexaFluor 488 goat anti-mouse or AlexaFluor 594 goat anti-rabbit (Invitrogen, ThermoFisher Scientific).

Samples were photographed using an Olympus SZX16 stereomicroscope under bright field (H\&E, Safranin O) or epifluorescence (excitation: $405 \mathrm{~nm}$ for DAPI; $488 \mathrm{~nm}$ (green) or $594 \mathrm{~nm}$ (red) for immunofluorescence.

\section{Biochemical composition}

To determine the biochemical composition of tissues and 3D constructs, dried samples were digested overnight at $65{ }^{\circ} \mathrm{C}$ at a concentration of $10 \mathrm{mg} / \mathrm{mL}$ in a digestion buffer ( $\mathrm{pH}$ 6.0) containing $2 \%$ papain (v/v, from Papaya latex; Sigma-Aldrich), $0.1 \mathrm{M}$ sodium acetate, $0.01 \mathrm{M}$ cysteine $\mathrm{HCl}$, and $0.05 \mathrm{M}$ EDTA. Concentrated $\mathrm{NaOH}$ was subsequently added to the digestion solution to adjust the $\mathrm{pH}$ to 7.0. Sulfated glycosaminoglycan (sGAG) content was quantified with a Blyscan Assay according to the manufacturer's instructions (Biocolor, Carrickfergus, UK). dsDNA content was determined using the Quant-iT Picogreen dsDNA assay (Invitrogen). Total collagen content was determined using a modified hydroxyproline assay. Briefly, $200 \mu \mathrm{L}$ of each sample was hydrolyzed with an equal volume of $4 \mathrm{~N} \mathrm{NaOH}$ at $121{ }^{\circ} \mathrm{C}$ for $75 \mathrm{~min}$, neutralized with an equal volume of $4 \mathrm{~N} \mathrm{HCl}$, and then titrated to an approximate $\mathrm{pH}$ of 7.0. The resulting solution was combined with $1.2 \mathrm{~mL}$ chloramine-T $(14.1 \mathrm{~g} / \mathrm{L})$ in buffer $(50 \mathrm{~g} / \mathrm{L}$ citric acid, $120 \mathrm{~g} / \mathrm{L}$ sodium acetate trihydrate, $34 \mathrm{~g} / \mathrm{L} \mathrm{NaOH}$, and $12.5 \mathrm{~g} / \mathrm{L}$ acetic acid) and allowed to stand at room temperature for $30 \mathrm{~min}$. The solution was then combined with $1.2 \mathrm{~mL}$ of $1.17 \mathrm{mM}$ p-dimethylaminobenzaldehyde in perchloric acid and placed in a $65{ }^{\circ} \mathrm{C}$ water bath for $20 \mathrm{~min} ; 200 \mu \mathrm{L}$ of each sample was added to a clear 96well plate, in duplicate, and absorbance at $550 \mathrm{~nm}$ was read. PureCol bovine collagen $(3.2 \mathrm{mg} / \mathrm{mL}$; Advanced Biomatrix) was serially diluted to provide a standard curve ranging from 0 to $1000 \mu \mathrm{g} / \mathrm{mL}$.

\section{Statistics}

Comparisons across multiple conditions or time points were made using a one-way or two-way analysis of variance (ANOVA) with Tukey post-hoc testing for multiple comparisons. When comparing two conditions, a 
Student's $t$ test was performed. Data are presented as mean \pm standard deviation. Experiments were performed with biological triplicates over at least three independent trials. Sample sizes are indicated in figure legends. Statistical significance was considered at $p<0.05$.

\section{Results \\ Characterization of soluble tendon- and cartilage-derived extracellular matrix}

The decellularization protocol successfully reduced cellular content from both tendon and cartilage, as evidenced by the absence of nuclei on both H\&E- and DAPI-stained sections (Fig. $1 \mathrm{a}-\mathrm{h}$ ), as well as a significant reduction in dsDNA content (Fig. 1i). Per dry weight, the total collagen contents of native and decellularized tendon were equivalent, while decellularized cartilage exhibited a significant increase in collagen content with a corresponding loss in sGAG content (Fig. $1 j-k$ ). The majority of decellularized tissue powder was insoluble in urea (Fig. 11) but was homogenously digested by the acid-pepsin solution (Fig. $1 \mathrm{~m}$ ). As a result, as shown in Fig. 1n and o, SDS-PAGE showed that urea-extracted tendon ECM (tECM) and cartilage ECM (cECM) were enriched for low to moderate molecular weight proteins, with only faint bands corresponding to collagen $\alpha$ chains. Conversely, the pepsin-digested tendon (tAP) and cartilage (cAP) were principally composed of collagen types I and II, respectively, with very faint bands found in the low to moderate molecular weight regions. The prominent streak in the well of native cartilage is an artifact attributable to the high proteoglycan content (Fig. 1o). tECM and cECM possessed a higher growth factor content than their pepsindigested counterparts, with notable differences in basic fibroblast growth factor (bFGF) and TGF- $\beta 1$ (Additional file 2: Table S2).

\section{Effect of soluble ECM on human MSCs in 2D culture} Human MSCs were grown as 2D cultures seeded on plastic in one of six medium conditions (Fig. 2a). Pepsin-digested and urea-extracted ECM supplementation enhanced cell proliferation, with the urea-extracted groups showing the greatest effect by day 7 (Fig. 2b). Only the urea-extracted ECMs upregulated tissuespecific transcription factors; tECM preferentially enhanced $S C X$ expression while cECM upregulated SOX9 expression (Fig. 2c). No soluble ECM preparation affected expression of the osteogenic marker RUNX2. Collagen type II (COL2A1) and aggrecan (ACAN) expression was not detectable, while collagen type I (COL1A1) was only significantly upregulated by TGF- $\beta 3$, which also greatly increased $S C X$ expression (Fig. 2c). MSCs grown in tECM-supplemented medium possessed a spindle-shaped morphology, while cECM and, to a lesser extent, TGF- $\beta 3$ supplementation produced a cobblestone morphology (Fig. 2d).

\section{Effect of soluble ECM on MSCs seeded on aligned nanofibers}

MSCs seeded on aligned PCL nanofibers became elongated in the direction of the fibers (data not shown). TGF- $\beta 3$ supplementation upregulated both tenogenic (SCX, TNC, COL3A1, COL1A1) and chondrogenic (SOX9, COL10A1) markers, while tECM supplementation enhanced expression of tenogenic markers only (Fig. 3b). cECM modestly increased tenogenic markers (SCX, TNC, COL3A1) but upregulated chondrogenic markers (SOX9, COL2A1, COL1OA1) to an equivalent or greater extent than TGF- $\beta 3$; $c E C M$ also upregulated RUNX2. All supplements decreased gene expression of the cartilage proteoglycan $A C A N$ and bone protein osteocalcin $(O C N)$. Paralleling the expression pattern of $S C X$, an upstream driver of tenomodulin (TNMD) [41], confocal microscopy revealed the greatest immunostaining intensity for Tnmd in the TGF- $\beta 3$ group. However, tECM enhanced Tnmd production to a greater extent than cECM (Fig. 3c).

\section{Effect of soluble ECM on MSC pellets}

Total and relative sGAG contents were increased in pellets cultured in supplemented medium (Fig. 4b). TGF- $\beta 3$ and $\mathrm{cECM}$ supplementation increased total sGAG to a similar extent, but cECM was superior when sGAG content was normalized to dsDNA content (Fig. 4b). In terms of gene expression (Fig. 4c), TGF- 33 preferentially promoted a chondrogenic phenotype as shown by increased expression of $S O X 9, A C A N$, and COL2A1. tECM promoted a tenogenic phenotype with robust upregulation of SCX, MKX,COL3A1, and COL1A1, with more modest effects on chondrogenic and osteogenic markers. Similarly, cECM had a negligible or inhibitory effect on tenogenic markers but promoted chondrogenesis to an equivalent or greater degree than TGF- $\beta 3$. However, cECM also upregulated osteogenic markers most strongly, as seen in expression patterns of COL10A1 (hypertrophic marker), RUNX2, ALP, and OCN (Fig. 4c). Histological analysis of pellets showed a pattern that was consistent with assays for biochemical composition and gene expression. Namely, TGF- $\beta 3$ and cECM enhanced proteoglycan and collagen II deposition while tECM pellets showed the greatest collagen I staining intensity (Fig. 5).

\section{Effect of TGF- $\beta$ inhibition on bioactivity of soluble ECM}

The activity of endogenous TGF- $\beta$ in $\mathrm{tECM}$ and $\mathrm{cECM}$ was blocked using SB-431542, a TGF- $\beta$ receptor type 1 antagonist [40] that was added at $10 \mu \mathrm{M}$ to pellet culture media (Fig. 6a). Treatment with SB-431542 significantly 


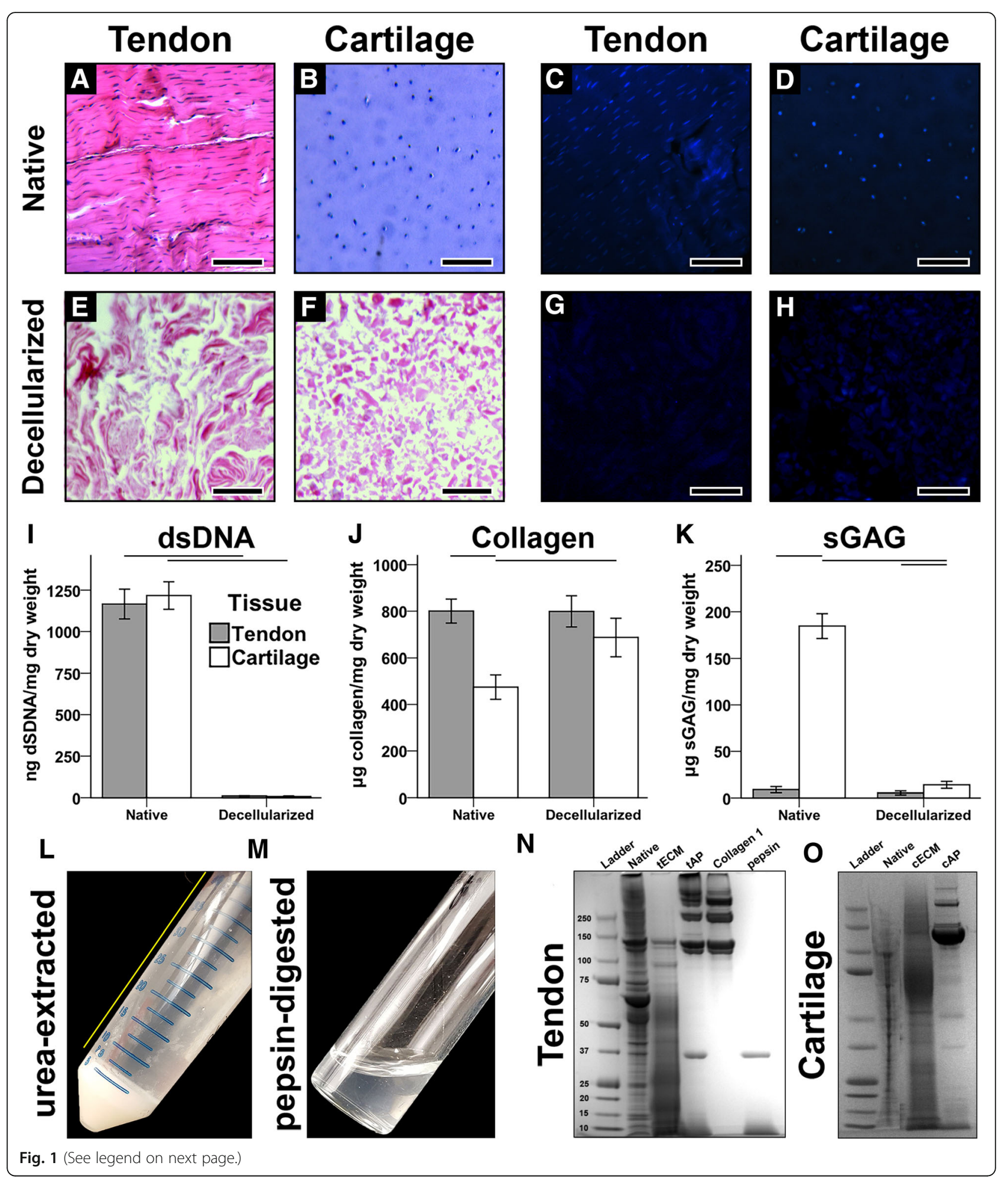


(See figure on previous page.)

Fig. 1 Characterization of soluble tendon- and cartilage-derived extracellular matrix. a-d Prior to decellularization, nuclei are clearly present in native tendon and cartilage tissues, as shown through H\&E and DAPI staining. $\mathbf{e}-\mathbf{h}$ Following decellularization, no nuclei are visible. Scale bar $=200 \mu \mathrm{m}$. i dsDNA contents were significantly reduced in decellularized tissues compared to native tissues $(p<0.001, n=8)$. $\mathbf{j}$ Collagen content in native and decellularized tendon was equivalent, but was increased in decellularized cartilage vs. native cartilage $(p<0.05, n=8)$. k Sulfated glycosaminoglycan $(s G A G)$ content was higher in cartilage tissues than tendon tissues, regardless of decellularization step $(p<0.05)$, but decellularized cartilage contained significantly less SGAG than native cartilage $(p<0.001, n=8)$. For (i-k), statistically significant differences are indicated by overlying horizontal lines. I Urea extraction yielded an insoluble and soluble fraction. The soluble supernatant (yellow line) was collected. $\mathbf{m}$ Pepsin digestion yielded a homogeneous slurry. $\mathbf{n}, \mathbf{o}$ SDS-PAGE analysis of tendon ( $\mathbf{n}$ ) and cartilage (o) tissues at different stages of decellularization and solubilization. CAP acid-pepsin digested cartilage extracellular matrix, CECM urea-extracted cartilage extracellular matrix, tAP acid-pepsin digested tendon extracellular matrix, EECM urea-extracted tendon extracellular matrix

reduced the anabolic effects of TGF- $\beta$ and $\mathrm{cECM}$ on pellets, as evidenced by the loss of proteoglycan staining (Fig. 6b) and sGAG content (Fig. 6c; Additional file 3: Figure S1). Gene expression analysis showed that SB431542 treatment eliminated the tenogenic effect of tECM and the chondrogenic effect of TGF- $\beta$ (Fig. 6d). Interestingly, $\mathrm{cECM}$ supplementation still promoted significant increases in SOX9, ACAN, and COL2A1 expression despite treatment with SB-431542 (Fig. 6d), although these increases were far weaker than pellets treated with cECM in the absence of SB-431542 (Fig. 4c). ECM-mediated upregulation of osteogenic markers, alkaline phosphatase $(A L P)$ and $O C N$, also persisted in the presence of TGF- $\beta$ inhibition.

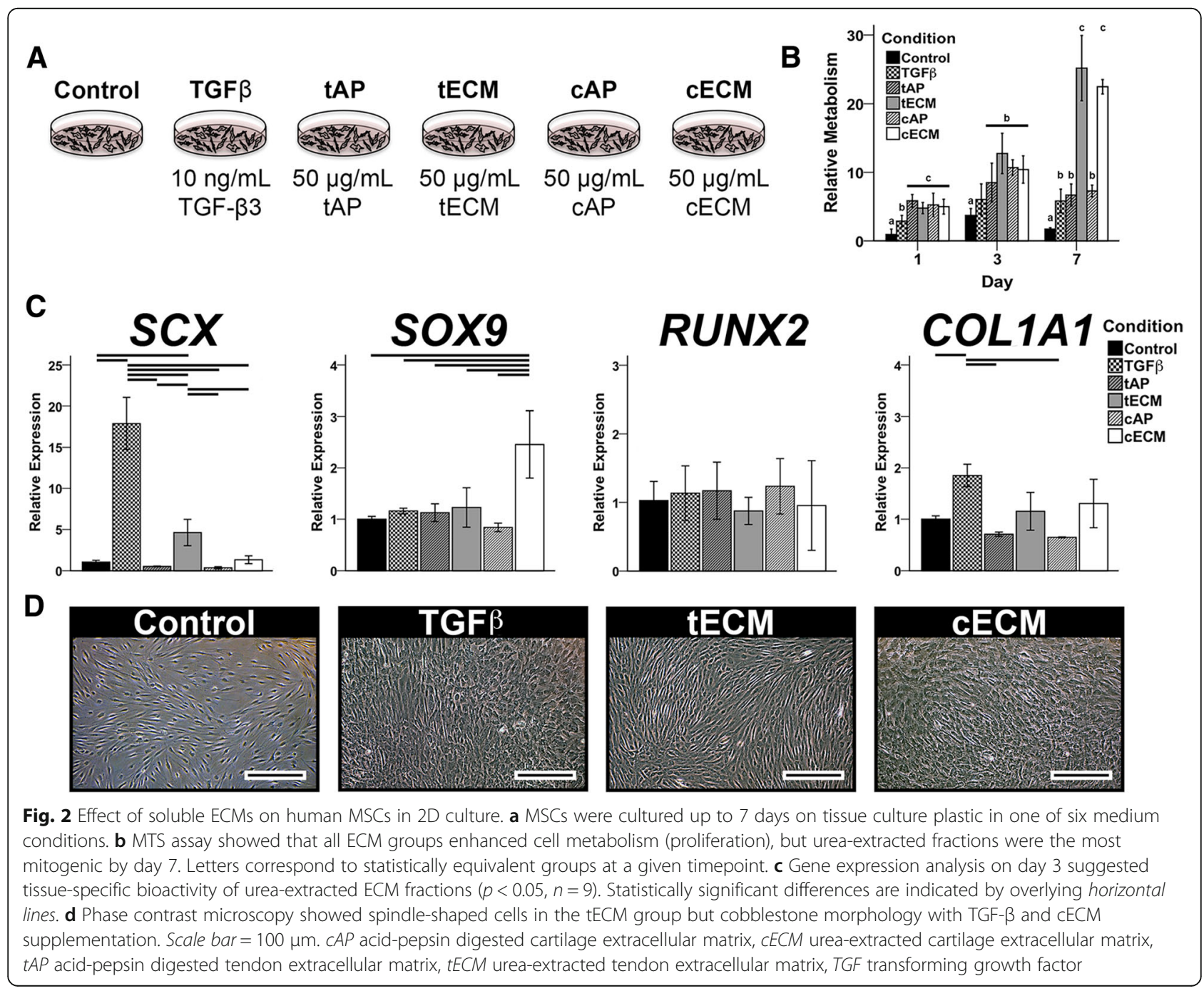




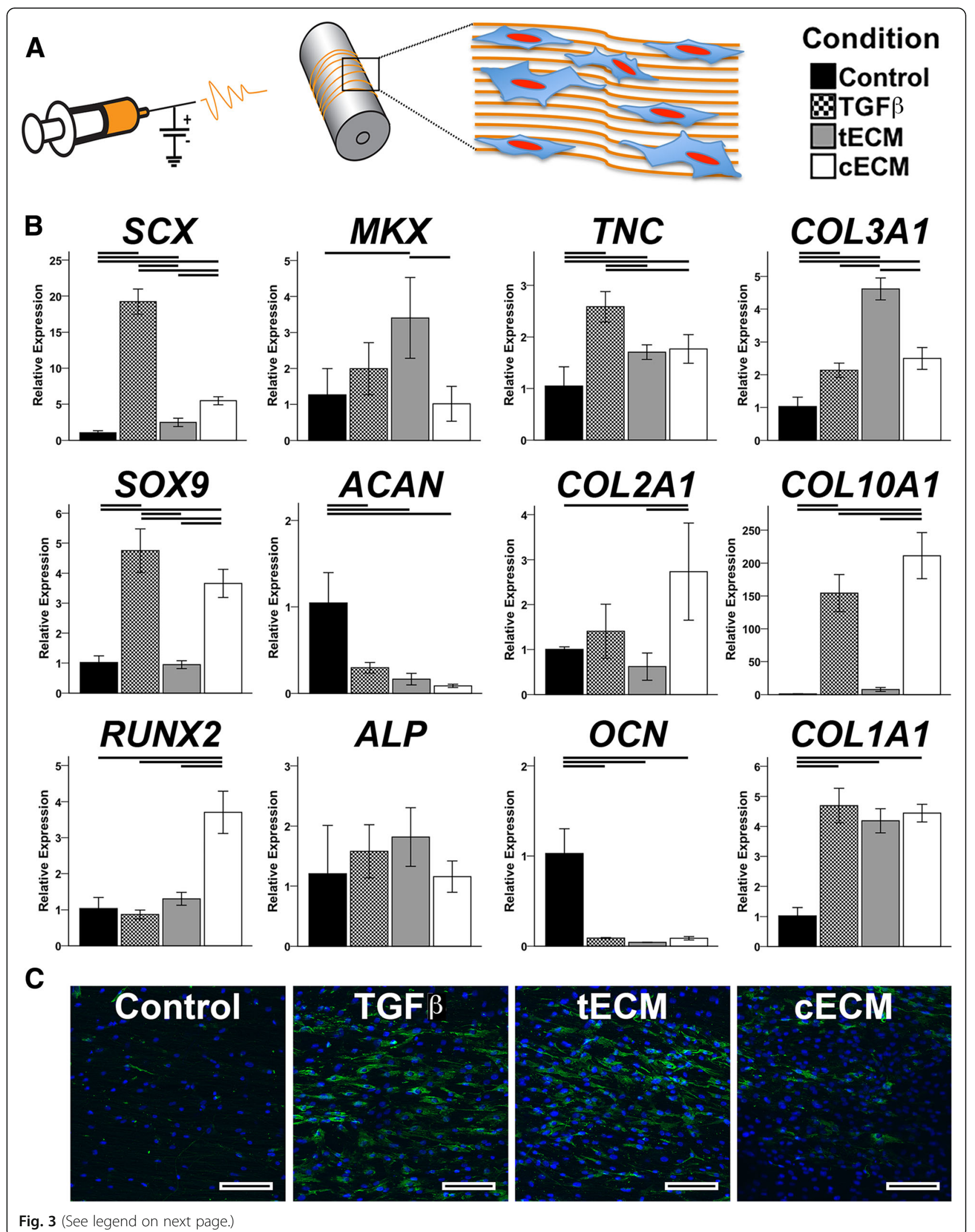


(See figure on previous page.)

Fig. 3 Effect of soluble ECM on MSCS seeded on aligned nanofibers. a MSCs were cultured on aligned PCL nanofibers in one of four medium conditions. $\mathbf{b}$ Gene expression analysis on day 14 showed tenogenic and chondrogenic effects due to TGF- $\beta$ supplementation. tECM supplementation promoted a tenogenic phenotype while cECM upregulated chondrogenic markers and RUNX2. Both TGF- $\beta$ and cECM increased expression of the hypertrophic marker COL1OA1 $(p<0.05, n=9)$. Statistically significant differences are indicated by overlying horizontal lines. $\mathbf{c}$ Immunofluorescence staining of tenomodulin shows increasing intensity in the following order: control $<\mathrm{CECM}<\mathrm{tECM}<\mathrm{TGF}-\beta ;$ Tnmd $=$ green, nuclei $=$ blue. Scale bar $=100 \mu \mathrm{m}$. CECM urea-extracted cartilage extracellular matrix, $t E C M$ urea-extracted tendon extracellular matrix

\section{Independent and synergistic effects of CECM and TGF- $\beta$ on chondrogenesis of MSCs seeded in 3D photocrosslinked GelMA hydrogels}

MSCs were seeded in photocrosslinked GelMA hydrogels and cultured in chondrogenic medium (with or without TGF- $\beta$ supplementation) for up to 21 days (Fig. 7a). On day 7, the inclusion of $\mathrm{CECM}$ within the hydrogels had independently upregulated chondrogenic markers $S O X 9, A C A N$, and $C O L 2 A 1$, as well as the ratio of COL2A1:COL1A1, despite a modest increase in COL1A1 (Fig. 7b). RUNX2 expression was also upregulated by $\mathrm{CECM}$ on day 7 , but was equivalent to controls (and returned to baseline) by day 21. Supplementation of culture medium with TGF- $\beta$ dramatically enhanced the expression of chondrogenic markers, compared to controls, on days 7 and 21. The effect was further enhanced when cECM was mixed with the GelMA hydrogel, suggesting a synergistic effect between the cECM and TGF- $\beta$ (Fig. 7b). This synergistic effect was also confirmed upon analysis of the biochemical composition of MSC-seeded hydrogels (Fig. 7c). Importantly, a cellular cECM-containing GelMA hydrogels had negligible sGAG content (data not shown), suggesting that the observed group differences are attributable to the effects of cECM on MSCs rather than sGAG contained within cECM solution.

\section{Discussion}

Given the conservation of ECM proteins across species, the utility of decellularized tissues as biomaterials capable of promoting tissue-specific cell phenotypes is theoretically and empirically supported $[42,43]$. Nevertheless, there is an inherent trade-off between tissue processing and retention of bioactive cues [16]. While sufficient decellularization is required to mitigate an adverse immune response to the implanted scaffold [44], it is uncertain which elements of the ECM must be preserved in order to retain homologous bioactivity. Pepsin digestion of decellularized ECM yields viscous slurries capable of undergoing thermoresponsive gelation when $\mathrm{pH}$ balanced $[38,45]$, providing an attractive biomaterial for minimally invasive cell delivery to irregularly shaped defects. On the other hand, characterization of pepsin-digested ECM is seldom performed.
Our group [35] and others [32, 46] have recently reported that pepsin solubilization produces digests composed principally of structural ECM proteins, especially collagen; it should be pointed out that acid-pepsin digestion is the longstanding, classic method of tissue collagen isolation [47]. A similar finding was seen in this study. Notably, small to moderate molecular weight proteins were abundantly found in urea-extracted ECM while the respective collagen $\alpha$ chains constituted the majority of protein found in pepsin-digested ECM solutions. These compositional differences were demonstrated both qualitatively through SDS-PAGE (Fig. 1n and o) and quantitatively through a growth factor array (Additional file 2: Table S2). The compositional differences resulting from solubilization protocols presumably underlie the observed differences in bioactivity mediated by the ECM when delivered as medium supplements to MSCs cultured on 2D plastic. However, it may be argued that higher concentrations of pepsin-digested ECMs would be required to induce similar effects as ureaextracted ECMs, given the relative predominance of collagens (at the expense of small to moderate molecular weight proteins) in the former. To that end, supplementation of medium with a ten-fold higher concentration of pepsin-digested ECMs (i.e., $500 \mu \mathrm{g} / \mathrm{mL}$ ) did not alter their effects of MSC proliferation or differentiation (data not shown). Similarly, when MSCs were seeded in 3D thermoresponsive hydrogels derived from pepsindigested ECMs, tissue-specific bioactivity did differ between groups (Additional file 4: Figure S2). While limited, the literature corroborates these findings. Pati et al. [32] reported only a $\sim 1.5$-fold increase in SOX9 and COL2A1 expression when human MSCs were seeded in cAP hydrogels, as compared to collagen I hydrogels. Likewise, two related studies $[29,48]$ found a negligible effect of pepsin-digested cartilage ECM, compared to controls, in enhancing chondrogenesis.

In contrast, we previously found that treatment with tECM, a preparation of urea-extracted tendon ECM, upregulated expression of tenogenic markers, with concurrent downregulation of osteogenic markers, in MSCs cultured in a hydrogel under static uniaxial tension [37]. Zhang et al. [36] reported similar tissuespecific findings when coating tissue culture dishes with urea-extracted ECM derived from skin, skeletal 


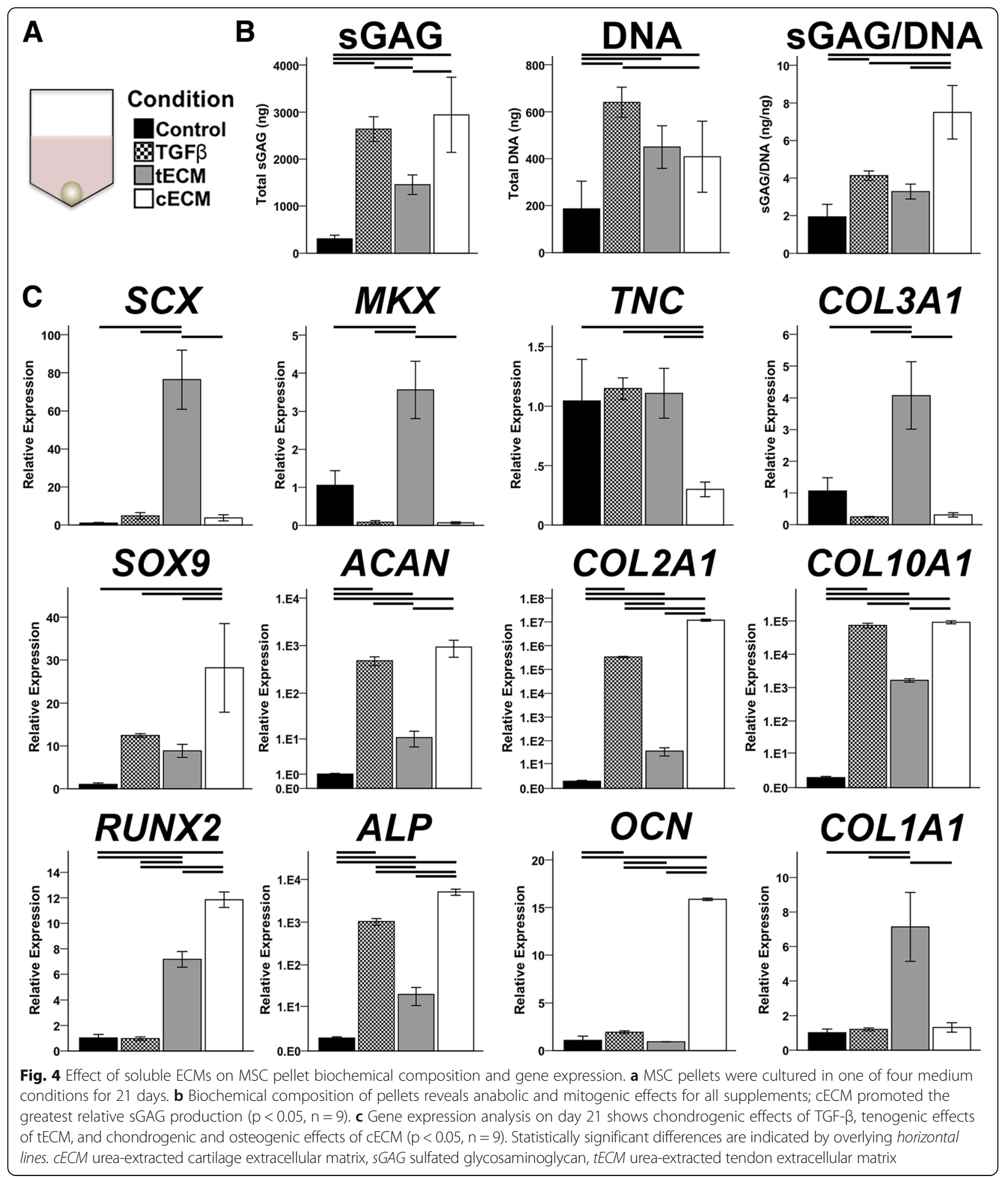

muscle, and liver. Building on these findings, this study showed that urea-extracted tECM and cECM upregulated tissue homologous transcription factors (i.e., $S C X$ and $S O X 9$, respectively) in MSCs grown on $2 \mathrm{D}$ plastic, while exogenous TGF- $\beta 3$ preferentially upregulated SCX alone. However, these effects were not sustained beyond 7 days, likely attributable to the stress of sustained serum-starvation coupled with the nonphysiologic biophysical microenvironment (i.e., 2D culture on plastic). 


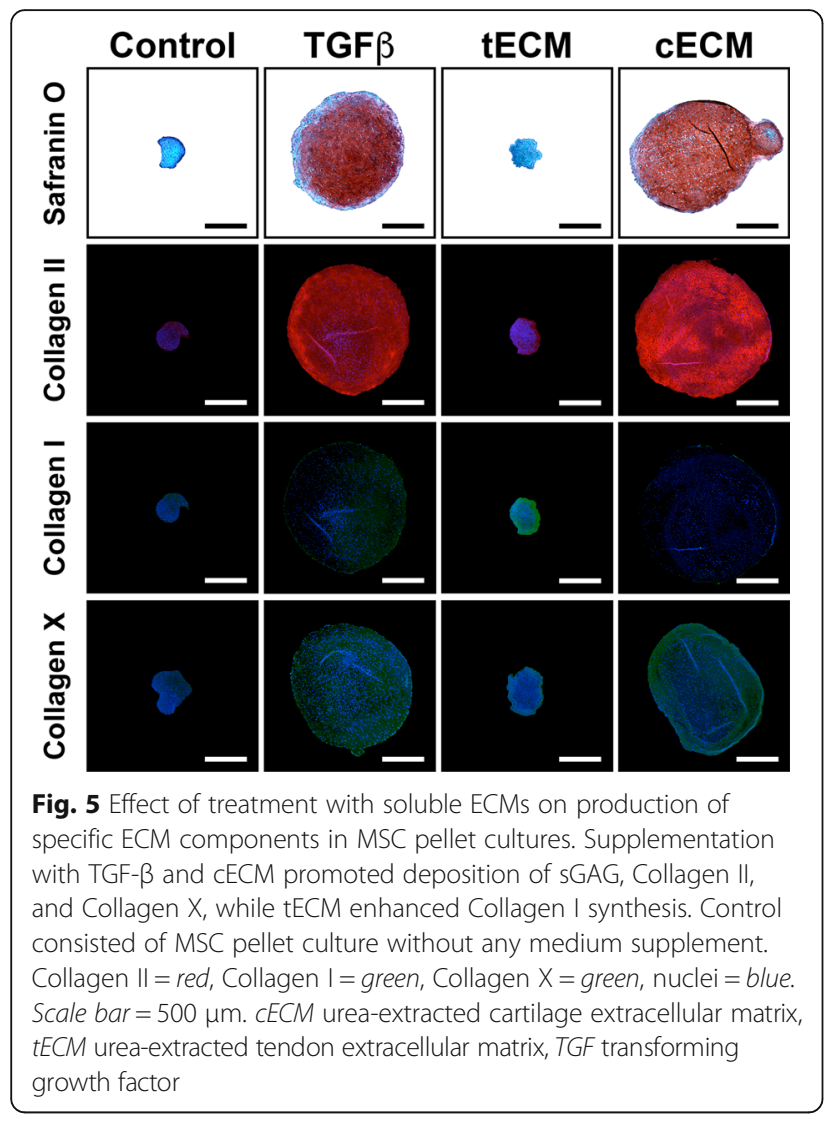

Nevertheless, as these initial experiments supported a superiority of urea-soluble ECM compared to pepsindigested ECM, we thereafter utilized only urea-extracted tECM and cECM to explore their tissue-specific bioactivity in two different 3D microenvironments: aligned electrospun nanofibers and cell pellets.

Electrospun nanofibers mimic the structural aspects of musculoskeletal tissue ECM (e.g., collagen fibrils) and are capable of directing cell behavior [49]. In particular, aligned nanofibers, reminiscent of the aligned collagen I fibrils of native tendon, have been shown to promote tenogenic differentiation of seeded stem cells $[5,6,50]$. Leung et al. [10] reported that supplementation with TGF- $\beta 3$ further enhanced tenogenesis in MSCs seeded on aligned chitosan-PCL nanofibers, while Kishore et al. [51] found no additional effect of bone morphogenetic protein (BMP)-12 supplementation with MSCs seeded on electrochemically aligned collagen threads. Similarly, nonaligned PCL nanofibers coated with pulverized tendon ECM showed little benefit over nanofibers alone in promoting a tenogenic phenotype of seeded MSCs [52]. These conflicting results suggest a complex interaction between physical and biochemical cues in directing cell differentiation. On the other hand, in this study, tECM supplementation was found to further upregulate expression of tenogenic markers, with negligible or inhibitory effects on chondrogenic and osteogenic expression, in MSCs seeded on aligned nanofibers. In comparison, cECM affected expression of chondrogenic markers to a similar extent as TGF- $\beta 3$, with a relatively diminished effect on tenogenic markers. Of note, $S C X$ is known to cooperatively regulate $S O X 9$ and COL $2 A 1$ expression in the context of chondrogenesis [53] despite its common categorization as a tendon-specific marker [54], perhaps explaining the small but significant upregulation of SCX mediated by cECM. In contrast, TGF- $\beta 3$ upregulated markers of both tenogenesis and chondrogenesis. Taken together, these findings support the tissue-specific bioactivity of urea-extracted ECMs when cells are seeded on aligned nanofibers. The results parallel those of Sun et al. [55], who reported increased osteogenesis when gelatin nanofibers were enhanced with noncollagenous proteins extracted from bone using a similar method to this study.

As aligned electrospun nanofibers were used to mimic the ultrastructure of native tendon, pellet cultures were employed as an in vitro assay to replicate the early condensation, and subsequent chondrogenesis, of mesenchymal cells in limb skeletal development. In this context, TGF- $\beta 3$ preferentially promoted chondrogenesis, while tECM and $\mathrm{CECM}$ promoted homologous gene expression (i.e., tenogenesis and chondrogenesis, respectively). TGF- $\beta$ is essential for mediating chondrogenesis in vivo $[13,56]$, yet its in vitro effect is variable and dependent on other microenvironmental cues. For instance, Lorda-Diez et al. [57, 58] identified several downstream regulators of TGF- $\beta$ signaling that mediated either fibrogenic or chondrogenic differentiation. Interestingly, in this study, inhibition of TGF- $\beta$ type 1 activin receptor-like kinase receptors ALK4, ALK5, and ALK7 by SB-431542 [40] largely abolished the tissue-specific bioactivity of tECM and cECM, suggesting that TGF- $\beta$ signaling is necessary, but not sufficient, to explain their tissue-specific effects.

A growth factor array analysis revealed significant differences in composition between tECM and cECM; it is possible that the greater concentrations of bFGF, BMP5 , and BMP-7 present in cECM mediated the cartilagespecific effects. However, given their role in bone formation [59], the additional BMPs found in cECM may also have contributed to the noted upregulation of hypertrophic and osteogenic markers seen in this study, although TGF- $\beta$ alone also induced some degree of hypertrophy in pellet cultures. The finding of cartilage ECM-induced hypertrophy has also been recently reported in similar studies $[60,61]$. Indeed, the stability of the chondrogenic phenotype remains a persistent challenge in cartilage tissue engineering [15]. It is possible that the use of $\mathrm{CECM}$ derived from adult animals, either 


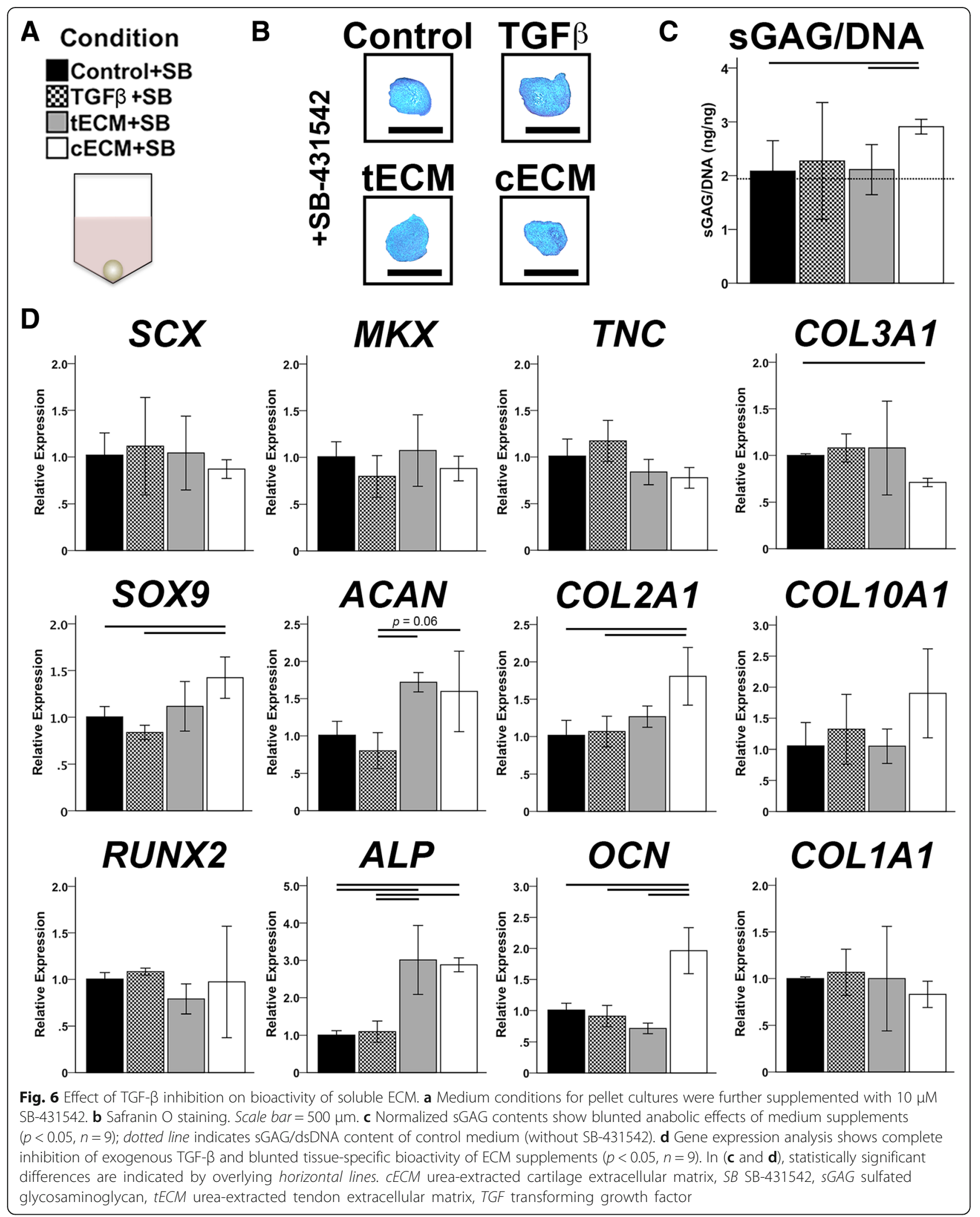




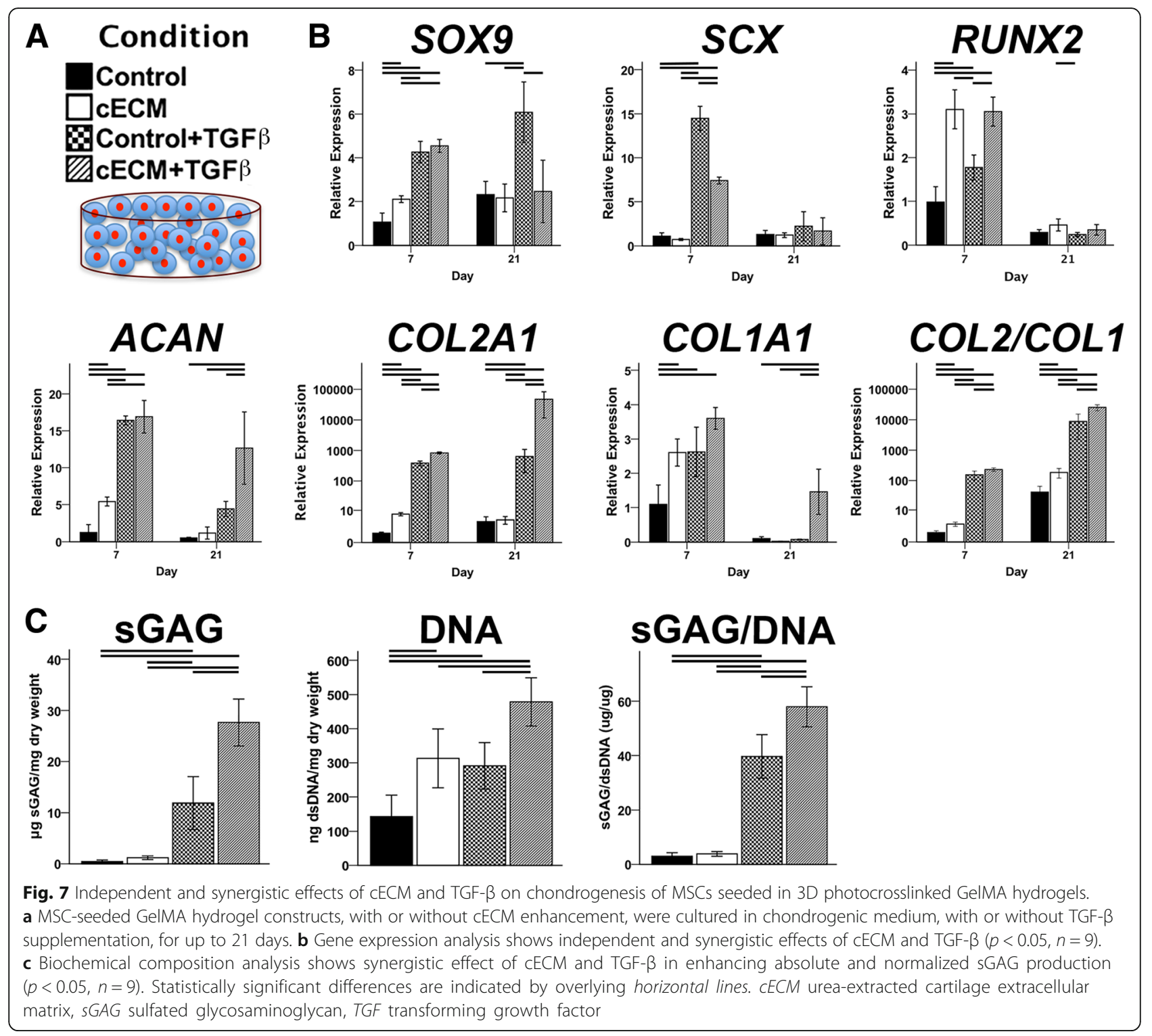

alone or in combination with other prochondrogenic factors, could promote chondrogenic differentiation with less hypertrophy, as the delineation between articular cartilage and subchondral bone (with obvious vasculature) is apparent (Additional file 5: Figure S3), allowing for the isolation of cartilage ECM alone. As shown in the growth factor array data (Additional file 2: Table S2), cECM from 2- to 3-year-old animals contains a lower concentration of growth factors than CECM from 6- to 8-week-old animals (as used in this study), but also greatly reduced levels of BMPs. Clearly, further elucidation of the composition of the soluble ECM preparations, and the interactions among these elements, will be necessary to expand on the findings obtained herein.

We propose that inclusion of urea-extracted ECM may be considered as a component of engineered scaffolds to accelerate or enhance the differentiation of encapsulated MSCs towards a particular tissue-specific lineage. The inclusion of cartilage ECM structural proteins such as collagen type VI [62], collagen type II, and proteoglycans $[63,64]$ within MSC-seeded hydrogels has been found to enhance chondrogenic differentiation. Similarly, Almeida et al. $[28,65]$ reported similar improvements when using decellularized cartilage ECM particles. In this study, cECM was mixed with photocrosslinkable GelMA hydrogels, a biomaterial which we previously found to support robust chondrogenesis [8]. cECM independently enhanced chondrogenesis at day 7 , but the chondroinductive effect decreased by day 21 . Rather, medium supplementation with TGF- $\beta$ was required for sustained upregulation of chondrogenic markers, with corresponding deposition of cartilage ECM proteins; this finding 
agrees with related work $[27,28,65]$. Despite the apparent necessity of exogenous TGF- $\beta$ for robust cartilage formation, $c E C M$ within the hydrogel interacted synergistically with the supplemented TGF- $\beta$, as demonstrated by the greatest increases in chondrogenic gene expression and sGAG deposition seen in the $\mathrm{cECM}+$ TGF- $\beta$ group. Given these results, we are now developing cECM-enhanced hydrogels with controlled release of encapsulated TGF- $\beta$, potentially obviating the need for medium supplementation and improving the translational applicability of this approach.

Although this study found that urea-extracted ECM, rather than pepsin-digested ECM, is capable of promoting tissue-specific cell phenotypes across multiple culture conditions, we did not explore the many other benefits reported for pepsin-solubilized ECM. In particular, pepsin ECM digests have been found to enhance in vitro cell migration [34], proliferation [66], and macrophage polarization [67], effects influenced by tissue source [68], animal age [69], and fraction [70]. In vivo, ECM-mediated effects on macrophage polarization, and the broader inflammatory response, at least partially explain the benefit of ECMs in promoting constructive remodeling (i.e., improved healing) [71, 72]. To what extent in vitro assays for tissue-specific differentiation are predictive of enhanced in vivo healing remains unknown. For instance, Keane et al. [34] and Wolf et al. [45] found that ECM hydrogels derived from esophagus and skeletal muscle, respectively, promoted tissuespecific differentiation of cells in vitro, but their effects in vivo were not superior to ECM hydrogels derived from heterologous tissues. The effects of urea-extracted ECM fractions on macrophage polarization and in vivo healing were beyond the scope of the present investigation, but certainly are worthy of future inquiry. Indeed, it is well recognized that successful regeneration of musculoskeletal tissues will require a greater understanding of the intersection of biomimetic biomaterials that are capable of guiding tissue-specific cell phenotypes, with the resulting inflammatory response elicited when such constructs are implanted in vivo.

\section{Conclusions}

In this study, decellularized tendon and cartilage ECMs were solubilized either by pepsin digestion or urea extraction. The effects of these preparations on human MSC behavior were evaluated in 2D and 3D cultures. Pepsin-digested tendon and cartilage ECMs did not promote tissue-specific differentiation, as compared to controls, while urea-extracted fractions were mitogenic and upregulated homologous cell phenotypes. When MSCs were cultured as pellets, inhibition of endogenous TGF$\beta$ signaling using SB-431542 negated the tissue-specific inductivity of urea-extracted ECM, suggesting that endogenous TGF- $\beta$ activity is necessary, but not sufficient, to explain the homologous bioactivity of tECM and cECM. When added as a component of a photocrosslinkable GelMA hydrogel, cECM independently upregulated early chondrogenesis of encapsulated MSCs and synergistically enhanced chondrogenesis when exogenous TGF- $\beta$ was added as a medium supplement. Therefore, urea-extracted ECM fractions may be a promising biomaterial that, when combined with physically tunable scaffolds, can guide tissue-specific cell differentiation.

\section{Additional files}

Additional file 1: Table S1. Target gene primer sequences for $\mathrm{qPCR}$. (DOCX $14 \mathrm{~kb}$ )

Additional file 2: Table S2. Human growth factor array analysis of soluble tendon and cartilage ECM preparations. Growth factor concentrations $(\mathrm{pg} / \mathrm{mL})$ in $500 \mu \mathrm{g} / \mathrm{mL}$ soluble ECM preparations. (DOCX $15 \mathrm{~kb}$ )

Additional file 3: Figure S1. Effect of TGF- $\beta$ signaling inhibition on biochemical content of MSC pellets. Medium conditions for pellet cultures were further supplemented with $10 \mu \mathrm{M}$ SB-431542. Pellets supplemented with CECM exhibited elevated (albeit blunted) total sGAG and dsDNA contents compared to other medium conditions $(p<0.05$, $n=9$ ); dotted line indicates sGAG and dsDNA contents of control medium (without SB-431542). Statistically significant differences are indicated by overlying horizontal lines. (TIF $273 \mathrm{~kb}$ )

Additional file 4: Figure S2. Gene expression in cultures of MSCs seeded in 3D hydrogel derived from pepsin-digested ECM. MSCs were seeded in $5 \mathrm{mg} / \mathrm{mL}$ hydrogels of Collagen I (control), tAP, and CAP. ECM-derived hydrogels showed negligible tissue-specificity compared to controls. Statistically significant differences $(p<0.05, n=9)$ are indicated by overlying horizontal lines. (TIF $408 \mathrm{~kb}$ )

Additional file 5: Figure S3. Macroscopic image of femoral condyles from young ( $6-8$ weeks) and mature ( $2-3$ years) cows. The osteochondral interface is distinct in adult animals but indistinct in young animals, with clear vasculature seen in dissected cartilage pieces. (TIF 1663 kb)

\section{Abbreviations}

2D: Two-dimensional; 3D: Three-dimensional; ACAN: Aggrecan; ALP: Alkaline phosphatase; ANOVA: Analysis of variance; bFGF: Basic fibroblast growth factor; BMP: Bone morphogenetic protein; BSA: Bovine serum albumin; CAP: Acidpepsin digested cartilage extracellular matrix; CECM: Urea-extracted cartilage extracellular matrix; COL: Collagen; DAPI: 4',6-Diamidino-2-phenylindole; DMEM: Dulbecco's modified Eagle's medium; DMF: Dimethylformamide; ECM: Extracellular matrix; EDTA: Ethylenediaminetetraacetic acid; FBS: Fetal bovine serum; GAPDH: Glyceraldehyde 3-phosphate dehydrogenase; GelMA: Methacrylated gelatin; H\&E: Hematoxylin and eosin; HBSS: Hanks buffered salt solution; ITS: Insulin-transferrin-selenium; LAP: Lithium phenyl-2,4,6trimethylbenzoylphosphinate; MKX: Mohawk; MSC: Mesenchymal stem cell; OCN: Osteocalcin; PBS: Phosphate-buffered saline; PCL: Poly- $\varepsilon$-caprolactone; PMSF: Phenylmethylsulfonyl fluoride; PSF: Penicillin-streptomycin-fungizone; qPCR: Quantitative real-time polymerase chain reaction; RUNX2: Runt-related transcription factor 2; SCX: Scleraxis; SGAG: Sulfated glycosaminoglycan; SOX9: SRY-box 9; tAP: Acid-pepsin digested tendon extracellular matrix; tECM: Urea-extracted tendon extracellular matrix; TGF- $\beta$ : Transforming growth factor beta; THF: Tetrahydrofuran; TNC: Tenascin C; Tnmd: Tenomodulin

\section{Acknowledgements}

The authors would like to thank Dr. Paul Manner (University of Washington) for providing the clinical samples, Dr. Jian Tan for MSC isolation and characterization, and Dr. Hang Lin for providing the GelMA. 


\section{Funding}

This work is supported in part by grants from the Commonwealth of Pennsylvania Department of Health (SAP 4100050913), NIH (5R01 AR062947), and US Department of Defense (W81XWH-08-2-0032, W81XWH-14-2-0003, W81XWH-15-1-0104, and W81XWH-11-2-0143). BBR was a predoctoral trainee supported by the National Institute of Biomedical Imaging and Bioengineering, $\mathrm{NIH}$, Training Grant (T32EB001026).

\section{Availability of data and materials}

The datasets used and/or analyzed during the current study are available from the corresponding author on reasonable request.

\section{Authors' contributions}

BBR designed the study, performed experiments, analyzed data, interpreted results, and was the major contributor in writing the manuscript. GY performed experiments, analyzed data, and was a minor contributor in writing the manuscript. RST designed the study, interpreted results, procured funding, and was the major contributor in revising the manuscript. All authors read and approved the final manuscript.

\section{Competing interests}

The authors declare that they have no competing interests. Co-author Rocky S Tuan is the Editor-in-Chief of the journal.

\section{Consent for publication}

Not applicable.

\section{Ethics approval and consent to participate}

All human MSCs were obtained from three donors, with informed consent, undergoing total hip arthroplasty with Institutional Review Board approval (University of Washington and University of Pittsburgh).

\section{Publisher's Note}

Springer Nature remains neutral with regard to jurisdictional claims in published maps and institutional affiliations.

\section{Author details \\ ${ }^{1}$ Center for Cellular and Molecular Engineering, Department of Orthopaedic Surgery, University of Pittsburgh School of Medicine, 450 Technology Drive, Room 221, Pittsburgh, PA 15219, USA. ${ }^{2}$ McGowan Institute for Regenerative Medicine, University of Pittsburgh, Pittsburgh, PA 15219, USA. ${ }^{3}$ Department of Bioengineering, University of Pittsburgh Swanson School of Engineering, Pittsburgh, PA 15219, USA.}

\section{Received: 4 April 2017 Revised: 2 May 2017}

Accepted: 8 May 2017 Published online: 05 June 2017

\section{References}

1. Lomas AJ, Ryan CNM, Sorushanova A, Shologu N, Sideri Al, Tsioli V, et al. The past, present and future in scaffold-based tendon treatments. Adv Drug Del Rev. 2015;84:257-77.

2. Yang G, Rothrauff BB, Tuan RS. Tendon and ligament regeneration and repair: clinical relevance and developmental paradigm. Birth Defects Res C Embryo Today. 2013;99:203-22.

3. Makris EA, Gomoll AH, Malizos KN, Hu JC, Athanasiou KA. Repair and tissue engineering techniques for articular cartilage. Nat Rev Rheumatol. 2015;11:21-34.

4. Mollon B, Kandel R, Chahal J, Theodoropoulos J. The clinical status of cartilage tissue regeneration in humans. Osteoarthr Cartil. 2013;21:1824-33.

5. Moffat KL, Kwei ASP, Spalazzi JP, Doty SB, Levine WN, Lu HH. Novel nanofiber-based scaffold for rotator cuff repair and augmentation. Tissue Eng Part A. 2009;15:115-26.

6. Zhang C, Yuan HH, Liu HH, Chen X, Lu P, Zhu T, et al. Well-aligned chitosanbased ultrafine fibers committed teno-lineage differentiation of human induced pluripotent stem cells for Achilles tendon regeneration. Biomaterials. 2015;53:716-30.

7. Bian L, Guvendiren M, Mauck RL, Burdick JA. Hydrogels that mimic developmentally relevant matrix and $\mathrm{N}$-cadherin interactions enhance MSC chondrogenesis. Proc Natl Acad Sci. 2013;110:10117-22.

8. Lin H, Cheng AW-M, Alexander PG, Beck AM, Tuan RS. Cartilage tissue engineering application of injectable gelatin hydrogel with in situ visible- light-activated gelation capability in both air and aqueous solution. Tissue Eng Part A. 2014;20:2402-11.

9. Lai JH, Rogan H, Kajiyama G, Goodman SB, Smith RL, Maloney W, et al. Interaction between osteoarthritic chondrocytes and adipose-derived stem cells is dependent on cell distribution in three-dimension and transforming growth factor-beta 3 induction. Tissue Eng Part A. 2015;21:992-1002.

10. Leung M, Jana S, Tsao CT, Zhang MQ. Tenogenic differentiation of human bone marrow stem cells via a combinatory effect of aligned chitosanpolycaprolactone nanofibers and TGF-beta 3. J Mater Chem B. 2013;1:6516-24.

11. Madry H, Rey-Rico A, Venkatesan JK, Johnstone B, Cucchiarini M. Transforming growth factor beta-releasing scaffolds for cartilage tissue engineering. Tissue Eng Part B. 2014;20:106-25.

12. Havis E, Bonnin MA, Olivera-Martinez I, Nazaret N, Ruggiu M, Weibel J, et al. Transcriptomic analysis of mouse limb tendon cells during development. Development. 2014;141:3683-96.

13. Wang W, Rigueur D, Lyons KM. TGF beta signaling in cartilage development and maintenance. Birth Defects Res C Embryo Today. 2014;102:37-51.

14. Lorda-Diez Cl, Montero JA, Garcia-Porrero JA, Hurle JM. Divergent differentiation of skeletal progenitors into cartilage and tendon: lessons from the embryonic limb. ACS Chem Biol. 2014;9:72-9.

15. Somoza RA, Welter JF, Correa D, Caplan Al. Chondrogenic differentiation of mesenchymal stem cells: challenges and unfulfilled expectations. Tissue Eng Part B. 2014;20:596-608.

16. Crapo PM, Gilbert TW, Badylak SF. An overview of tissue and whole organ decellularization processes. Biomaterials. 2011;32:3233-43.

17. Benders KEM, van Weeren PR, Badylak SF, Saris DBF, Dhert WJA, Malda J. Extracellular matrix scaffolds for cartilage and bone regeneration. Trends Biotechnol. 2013;31:169-76.

18. Schulze-Tanzil G, Al-Sadi O, Ertel W, Lohan A. Decellularized tendon extracellular matrix - a valuable approach for tendon reconstruction? Cells. 2012;1:1010-28.

19. Yin Z, Chen $X$, Zhu T, Hu J-J, Song H-X, Shen W-L, et al. The effect of decellularized matrices on human tendon stem/progenitor cell differentiation and tendon repair. Acta Biomater. 2013;9:9317-29.

20. Ning $L$, Zhang YJ, Zhang Y, Qing Q, Jiang YL, Yang JL, et al. The utilization of decellularized tendon slices to provide an inductive microenvironment for the proliferation and tenogenic differentiation of stem cells. Biomaterials. 2015:52:539-50.

21. Youngstrom DW, Barrett JG, Jose RR, Kaplan DL. Functional characterization of detergent-decellularized equine tendon extracellular matrix for tissue engineering applications. PLoS One. 2013;8:e64151.

22. Schwarz S, Koerber L, Elsaesser AF, Goldberg-Bockhorn E, Seitz AM, Durselen L, et al. Decellularized cartilage matrix as a novel biomatrix for cartilage tissueengineering applications. Tissue Eng Part A. 2012;18:2195-209.

23. Schwarz S, Elsaesser AF, Koerber L, Goldberg-Bockhorn E, Seitz AM, Bermueller $C$, et al. Processed xenogenic cartilage as innovative biomatrix for cartilage tissue engineering: effects on chondrocyte differentiation and function. J Tissue Eng Regen Med. 2015;9:239-51.

24. Ozasa Y, Amadio PC, Thoreson AR, An K-N, Zhao C. Repopulation of intrasynovial flexor tendon allograft with bone marrow stromal cells: an ex vivo model. Tissue Eng Part A. 2014;20:566-74.

25. Rowland CR, Lennon DP, Caplan Al, Guilak F. The effects of crosslinking of scaffolds engineered from cartilage ECM Cross Mark on the chondrogenic differentiation of MSCs. Biomaterials. 2013;34:5802-12.

26. Rowland CR, Colucci LA, Guilak F. Fabrication of anatomically-shaped cartilage constructs using decellularized cartilage-derived matrix scaffolds. Biomaterials. 2016;91:57-72.

27. Almeida HV, Cunniffe GM, Vinardell T, Buckley CT, O'Brien FJ, Kelly DJ. Coupling freshly isolated CD44(+) infrapatellar fat pad-derived stromal cells with a TGF-3 eluting cartilage ECM-derived scaffold as a single-stage strategy for promoting chondrogenesis. Adv Healthc Mater. 2015:4:1043-53.

28. Almeida HV, Eswaramoorthy R, Cunniffe GM, Buckley CT, O'Brien FJ, Kelly DJ. Fibrin hydrogels functionalized with cartilage extracellular matrix and incorporating freshly isolated stromal cells as an injectable for cartilage regeneration. Acta Biomater. 2016;36:55-62.

29. Beck EC, Barragan M, Tadros MH, Kiyotake EA, Acosta FM, Kieweg SL, et al. Chondroinductive hydrogel pastes composed of naturally derived devitalized cartilage. Ann Biomed Eng. 2016:44:1863-80.

30. Kim MY, Farnebo S, Woon CYL, Schmitt T, Pham H, Chang J. Augmentation of tendon healing with an injectable tendon hydrogel in a rat achilles tendon model. Plast Reconstr Surg. 2014;133:645E-53E. 
31. Farnebo S, Woon CYL, Schmitt T, Joubert LM, Kim M, Pham H, et al. Design and characterization of an injectable tendon hydrogel: a novel scaffold for guided tissue regeneration in the musculoskeletal system. Tissue Eng Part A. 2014;20:1550-61.

32. Pati F, Jang J, Ha DH, Kim SW, Rhie JW, Shim JH, et al. Printing threedimensional tissue analogues with decellularized extracellular matrix bioink. Nat Commun. 2014;5:11

33. Kwon JS, Yoon SM, Shim SW, Park JH, Min KJ, Oh HJ, et al. Injectable extracellular matrix hydrogel developed using porcine articular cartilage. Int J Pharm. 2013;454:183-91.

34. Keane TJ, DeWard A, Londono R, Saldin LT, Castleton AA, Carey L, et al. Tissue-specific effects of esophageal extracellular matrix. Tissue Eng Part A. 2015:21:2293-300.

35. Lin H, Yang G, Tan J, Tuan RS. Influence of decellularized matrix derived from human mesenchymal stem cells on their proliferation, migration and multi-lineage differentiation potential. Biomaterials. 2012:33:4480-9.

36. Zhang YY, He YJ, Bharadwaj S, Hammam N, Carnagey K, Myers R, et al. Tissue-specific extracellular matrix coatings for the promotion of cell proliferation and maintenance of cell phenotype. Biomaterials. 2009;30:4021-8.

37. Yang G, Rothrauff BB, Lin H, Gottardi R, Alexander PG, Tuan RS. Enhancement of tenogenic differentiation of human adipose stem cells by tendon-derived extracellular matrix. Biomaterials. 2013;34:9295-306.

38. Wolf MT, Daly KA, Brennan-Pierce EP, Johnson SA, Carruthers CA, D'Amore $A$, et al. A hydrogel derived from decellularized dermal extracellular matrix. Biomaterials. 2012;33:7028-38.

39. Rothrauff BB, Numpaisal PO, Laura BB, Alexander PG, Debski RE, Musahl V, et al. Augmented repair of radial meniscus tear with biomimetic electrospun scaffold: an in vitro mechanical analysis. J Exp Orthop. 2016:3:23.

40. Inman GJ, Nicolas FJ, Callahan JF, Harling JD, Gaster LM, Reith AD, et al. SB431542 is a potent and specific inhibitor of transforming growth factor-beta superfamily type I activin receptor-like kinase (ALK) receptors ALK4, ALK5, and ALK7. Mol Pharmacol. 2002;62:65-74.

41. Shukunami C, Takimoto A, Oro M, Hiraki Y. Scleraxis positively regulates the expression of tenomodulin, a differentiation marker of tenocytes. Dev Biol. 2006;298:234-47

42. Valentin JE, Badylak JS, McCabe GP, Badylak SF. Extracellular matrix bioscaffolds for orthopaedic applications-a comparative histologic study. J Bone Jt Surg (Am). 2006;88A:2673-86.

43. Badylak SF, Freytes DO, Gilbert TW. Extracellular matrix as a biological scaffold material: structure and function. Acta Biomater. 2009;5:1-13.

44. Keane TJ, Londono R, Turner NJ, Badylak SF. Consequences of ineffective decellularization of biologic scaffolds on the host response. Biomaterials. 2012:33:1771-81

45. Wolf MT, Daly KA, Reing JE, Badylak SF. Biologic scaffold composed of skeletal muscle extracellular matrix. Biomaterials. 2012;33:2916-25.

46. DeQuach JA, Mezzano V, Miglani A, Lange S, Keller GM, Sheikh F, et al. Simple and high yielding method for preparing tissue specific extracellular matrix coatings for cell culture. Plos One. 2010;5(9):e13039.

47. Timpl R, Bruckner P, Fietzek P. Characterization of pepsin fragments of basement-membrane collagen obtained from a mouse-tumor. Eur $J$ Biochem. 1979:95:255-63.

48. Visser J, Levett PA, te Moller NCR, Besems J, Boere KWM, van Rijen MHP, et al. Crosslinkable hydrogels derived from cartilage, meniscus, and tendon tissue. Tissue Eng Part A. 2015;21:1195-206.

49. Li WJ, Laurencin CT, Caterson EJ, Tuan RS, Ko FK. Electrospun nanofibrous structure: a novel scaffold for tissue engineering. J Biomed Mater Res. 2002;60:613-21.

50. Chen JL, Zhang W, Liu ZY, Heng BC, Ouyang HW, Dai XS. Physical regulation of stem cells differentiation into teno-lineage: current strategies and future direction. Cell Tissue Res. 2015;360:195-207.

51. Kishore V, Bullock W, Sun XH, Van Dyke WS, Akkus O. Tenogenic differentiation of human MSCs induced by the topography of electrochemically aligned collagen threads. Biomaterials. 2012;33:2137-44.

52. Chainani A, Hippensteel KJ, Kishan A, Garrigues NW, Ruch DS, Guilak F, et al. Multilayered electrospun scaffolds for tendon tissue engineering. Tissue Eng Part A. 2013;19:2594-604

53. Furumatsu T, Shukunami C, Amemiya-Kudo M, Shimano H, Ozaki T. Scleraxis and E47 cooperatively regulate the Sox9-dependent transcription. Int J Biochem Cell Biol. 2010;42:148-56.
54. Schweitzer R, Chyung JH, Murtaugh LC, Brent AE, Rosen V, Olson EN, et al. Analysis of the tendon cell fate using Scleraxis, a specific marker for tendons and ligaments. Development. 2001;128:3855-66.

55. Sun $Y$, Jiang $Y$, Liu QJ, Gao T, Feng JQ, Dechow $P$, et al. Biomimetic engineering of nanofibrous gelatin scaffolds with noncollagenous proteins for enhanced bone regeneration. Tissue Eng Part A. 2013;19:1754-63.

56. Tuli R, Tuli S, Nandi S, Huang XX, Manner PA, Hozack WJ, et al. Transforming growth factor-beta-mediated chondrogenesis of human mesenchymal progenitor cells involves $\mathrm{N}$-cadherin and mitogenactivated protein kinase and Wnt signaling cross-talk. J Biol Chem. 2003;278:41227-36.

57. Lorda-Diez Cl, Montero JA, Diaz-Mendoza MJ, Garcia-Porrero JA, Hurle JM. beta ig-h3 potentiates the profibrogenic effect of TGF beta signaling on connective tissue progenitor cells through the negative regulation of master chondrogenic genes. Tissue Eng Part A. 2013;19:448-57.

58. Lorda-Diez Cl, Montero JA, Martinez-Cue C, Garcia-Porrero JA, Hurle JM. Transforming growth factors beta coordinate cartilage and tendon differentiation in the developing limb mesenchyme. J Biol Chem. 2009;284:29988-96

59. Lorda-Diez Cl, Montero JA, Choe S, Garcia-Porrero JA, Hurle JM. Ligand- and stage-dependent divergent functions of BMP signaling in the differentiation of embryonic skeletogenic progenitors in vitro. J Bone Miner Res. 2014:29:735-48.

60. Sutherland AJ, Beck EC, Dennis SC, Converse GL, Hopkins RA, Berkland CJ, et al. Decellularized cartilage may be a chondroinductive material for osteochondral tissue engineering. Plos One. 2015;10(5):e0121966.

61. Visser J, Gawlitta D, Benders KEM, Toma SMH, Pouran B, van Weeren PR, et al. Endochondral bone formation in gelatin methacrylamide hydrogel with embedded cartilage-derived matrix particles. Biomaterials. 2015;37:174-82.

62. Smeriglio P, Dhulipala L, Lai JH, Goodman SB, Dragoo JL, Smith RL, et al. Collagen VI enhances cartilage tissue generation by stimulating chondrocyte proliferation. Tissue Eng Part A. 2015;21:840-9.

63. Grogan SP, Chen X, Sovani S, Taniguchi N, Colwell Jr CW, Lotz MK, et al. Influence of cartilage extracellular matrix molecules on cell phenotype and neocartilage formation. Tissue Eng Part A. 2014;20:264-74.

64. Wang $\mathrm{T}$, Lai JH, Han L-H, Tong X, Yang F. Chondrogenic differentiation of adipose-derived stromal cells in combinatorial hydrogels containing cartilage matrix proteins with decoupled mechanical stiffness. Tissue Eng Part A. 2014;20:2131-9.

65. Almeida HV, Liu Y, Cunniffe GM, Mulhall KJ, Matsiko A, Buckley CT, et al. Controlled release of transforming growth factor-beta 3 from cartilage extracellular matrix-derived scaffolds to promote chondrogenesis of humanjoint-tissue-derived stem cells. Acta Biomater. 2014;10:4400-9.

66. Crapo PM, Tottey S, Slivka PF, Badylak SF. Effects of biologic scaffolds on human stem cells and implications for CNS tissue engineering. Tissue Eng Part A. 2014;20:313-23

67. Sicari BM, Dziki JL, Siu BF, Medberry CJ, Dearth CL, Badylak SF. The promotion of a constructive macrophage phenotype by solubilized extracellular matrix. Biomaterials. 2014:35:8605-12.

68. Meng FW, Sliyka PF, Dearth CL, Badylak SE. Solubilized extracellular matrix from brain and urinary bladder elicits distinct functional and phenotypic responses in macrophages. Biomaterials. 2015;46:131-40.

69. Tottey S, Johnson SA, Crapo PM, Reing JE, Zhang L, Jiang H, et al. The effect of source animal age upon extracellular matrix scaffold properties. Biomaterials. 2011;32:128-36

70. Slivka PF, Dearth CL, Keane TJ, Meng FW, Medberry CJ, Riggio RT, et al. Fractionation of an ECM hydrogel into structural and soluble components reveals distinctive roles in regulating macrophage behavior. Biomater Sci. 2014;2:1521-34

71. Brown BN, Londono R, Tottey S, Zhang L, Kukla KA, Wolf MT, et al. Macrophage phenotype as a predictor of constructive remodeling following the implantation of biologically derived surgical mesh materials. Acta Biomater. 2012;8:978-87.

72. Brown BN, Ratner BD, Goodman SB, Amar S, Badylak SF. Macrophage polarization: an opportunity for improved outcomes in and regenerative medicine. Biomaterials. 2012:33:3792-802. 